\title{
Creating a knowledge translation trainee collaborative: from conceptualization to lessons learned in the first year
}

\author{
Evelyn Cornelissen ${ }^{1 *}$, Robin Urquhart ${ }^{2}$, Vivian WY Chan ${ }^{3}$, Ryan T DeForge ${ }^{4}$, Heather L Colquhoun ${ }^{5}$, \\ Shannon Sibbald ${ }^{6}$ and Holly Witteman ${ }^{7}$
}

\begin{abstract}
Trainees (e.g., graduate students, residents, fellows) are increasingly identifying knowledge translation as their research discipline. In Canada, a group of trainees have created a trainee-initiated and trainee-led national collaborative to provide a vehicle for trainees to examine the diversity of knowledge translation research and practice, and to link trainees from diverse geographical areas and disciplines. The aim of this paper is to describe our experience and lessons learned in creating the Knowledge Translation Trainee Collaborative. In this meeting report, we outline the process, challenges, and opportunities in planning and experiencing the collaborative's inaugural meeting as participant organizers, and present outcomes and learnings to date.
\end{abstract}

\section{Background}

As the field of knowledge translation (KT) grows, trainees (e.g., graduate students, residents, fellows) are identifying KT as their research discipline. The most efficient way to advance the science of KT while developing new scholars will be to encourage new research collaborations and partnerships [1] and expose new researchers to multiple modes of inquiry and perspectives [2].

In 2008, KT Canada, along with its funding partners, established KT Summer Institutes (SI) to create opportunities for students involved in $\mathrm{KT}$ to learn from and connect with established KT researchers and other trainees [3]. These three- to four-day workshops have resulted in several subsequent collaborative efforts, including published papers $[4,5]$ and successful grant applications [6,7]. Following the 2008 SI, several trainees identified a need for ongoing training and peer networking opportunities, and accordingly set out to create a collaborative that might serve to complement or supplement groups led and populated by experts in the field.

\footnotetext{
* Correspondence: ecorneli@interchange.ubc.ca

${ }^{1}$ University of British Columbia - Okanagan, Faculty of Health and Social Development, 3333 University Way, Kelowna, B.C. V1V 1V7 Canada Full list of author information is available at the end of the article
}

After an initial (unsuccessful) attempt to align a trainee networking meeting with a national health services research conference, two trainees [EC and $\mathrm{VC}$ ] were awarded a grant [6], along with funding and in-kind support from other organizations, to hold an inaugural meeting to build such a collaborative. Thirteen additional SI participants [including RU, RD, $\mathrm{HC}$, and $\mathrm{HW}$ ] volunteered to plan the event. Following a formal application and review process supported by national KT experts, we held a two-day meeting in Winnipeg, Manitoba, 6 and 7 March 2010.

The aim of this paper is to describe our experience and lessons learned in creating the KT Trainee Collaborative (KTTC). We outline the process, challenges, and opportunities in planning and experiencing the KTTC inaugural meeting as participant organizers, and present outcomes and learnings to date.

\section{KTTC inaugural meeting}

The inaugural meeting followed six months of planning via teleconference and email. The planning committee established three meeting objectives: forming our network; identifying areas for collaboration; and, with KT experts, reviewing potential gaps and training areas in $\mathrm{KT}$ research. We developed an agenda toward these goals and distributed a call for applicants.

\section{C) Biomed Central}


Sixty-six applications were received from 14 Canadian universities. The applications were peer-reviewed by a group of planning committee members and $\mathrm{KT}$ experts. Review criteria included training, research interests, expectations, and anticipated contribution to the meeting. The aim of the review process was to assemble a group of trainees that could both contribute to and gain from capacity building in the field of KT. Thirty trainees attended the meeting: 11 from the planning committee and 19 accepted through the application process. Table 1 describes attendee characteristics.

The meeting involved four activities, interspersed by networking opportunities: setting the stage for future interaction/collaborations; goal-setting; KT expert-led discussion on potential gaps/training areas in $\mathrm{KT}$ research; and post-meeting planning. Dr. Ian Graham, Canadian Institutes of Health Research (CIHR) Vice President of KT, participated as the overall meeting facilitator.

\section{Setting the stage}

To begin the meeting, each attendee introduced her/ himself in a two-minute prepared talk describing her/his research, career stage, KT interests, and something about her/himself. These introductions oriented us to each other's work, provided opportunity to practice a fundamental skill in scholarship (concisely describing one's work to an interdisciplinary audience), and ensured that all attendees participated early on.

Two planning committee members [RD, HC] then facilitated a 'creating space' exercise to establish principles for interaction and a sense of 'safety.' We acknowledged that over time our 'space' would likely take different forms because it was expected that, going forward, the KTTC would meet both in-person and virtually. However, the focus of this exercise was to co- construct shared principles for relating to and with one another in the context of this meeting. We also acknowledged that all shared spaces are inherently characterized by competing interests, agendas, needs, and experiences. Our aim was to encourage these interests and to conceive of new ways of working together wherein we each feel included and valued. The facilitators invited small groups to consider questions about creating an inclusive and engaging workspace, then collated responses to form a foundation of shared understandings upon which we continued our meeting.

\section{Goal setting}

To make sense of our group's goals and expectations, first, each attendee identified his/her individual goals. Then, we iteratively and thematically categorized individual goals into four collective goals: networking, collaborative learning, collaborative work, and professional development. Although it was evident that attendees held diverse research interests in a broad range of health areas, the four collective goals reflected our common perspectives and desires.

\section{Expert-led discussions}

KT experts presented their perspectives and experiences in three different areas identified as representing fruitful areas for further research and training: behavioural theory in policy/decision support (Dr. Jamie Brehaut [8]), unintended consequences of KT (Dr. Maria Mathews [9]), and critical/qualitative inquiry in KT (Dr. Annette J. Browne [10]). The experts then facilitated small group discussions based on their presentation topics.

\section{Post-meeting planning}

We ended the meeting by developing a post-meeting plan. We brainstormed activities to help us meet our collective goals, and elected a Steering Committee to oversee activities and establish a governance structure.

Table 1 Attendee characteristics

\begin{tabular}{|c|c|c|}
\hline & $\begin{array}{l}\text { Planning Committee }(\mathrm{n}=11) \\
\text { Count (percent) Number of institutions represented } \\
\text { [institution names] }\end{array}$ & $\begin{array}{l}\text { Successful Applicants }(\mathrm{n}=19) \\
\text { Count (percent) Number of institutions represented [institution names] }\end{array}$ \\
\hline Gender & $\begin{array}{l}1 \text { male }(9 \%) \\
10 \text { female }(91 \%)\end{array}$ & $\begin{array}{l}5 \text { male }(26 \%) \\
14 \text { female }(74 \%)^{*}\end{array}$ \\
\hline Province & $\begin{array}{l}1 \text { Nova Scotia (9\%) [Dalhousie University] } \\
1 \text { Prince Edward Island (9\%) [University of Prince Edward } \\
\text { Island] } \\
4 \text { Ontario (36\%) } 2 \text { universities, } 1 \text { hospital [University of } \\
\text { Western Ontario; McMaster University; St. Michael's Hospital] } \\
1 \text { Manitoba (9\%) [University of Manitoba] } \\
1 \text { Alberta (9\%) [University of Calgary] } \\
2 \text { British Columbia (18\%) } 1 \text { university [University of British } \\
\text { Columbia] } \\
1 \text { University of Michigan (9\%) }\end{array}$ & $\begin{array}{l}1 \text { Nova Scotia (5\%) [Dalhousie University] } \\
2 \text { Quebec (11\%) } 2 \text { universities [McGill University; Universite de Laval] } \\
12 \text { Ontario (63\%) } 6 \text { universities [University of Waterloo; University of Western } \\
\text { Ontario; McMaster University; University of Ottawa; York University; } \\
\text { University of Toronto] } \\
1 \text { Manitoba (5\%) [University of Manitoba] } \\
2 \text { Alberta (11\%) } 1 \text { university [University of Alberta] } \\
1 \text { British Columbia (5\%) [University of British Columbia] }\end{array}$ \\
\hline Training & $\begin{array}{l}1 \text { Post Doctoral/Fellows (9\%) } \\
9 \text { Doctoral }(82 \%) \\
1 \text { Research Staff }(9 \%)\end{array}$ & $\begin{array}{l}5 \text { Post Doctoral/Fellows (26\%) } \\
13 \text { Doctoral }(68 \%) \\
1 \text { Master's (5\%) }\end{array}$ \\
\hline
\end{tabular}

*The high percentage of female participants is representative of the proportion of applicants who were female. 
We also reached agreement on preferred technological mechanisms to support ongoing collaboration with limited resources.

\section{Meeting evaluation}

Using a 'two stars and a wish' exercise to garner feedback, wherein attendees were asked to list two things about the meeting they enjoyed and one thing they would like to see changed or improved, attendees indicated they felt: encouraged to be engaged in the process ('an interactive, open, and respectful atmosphere'); accomplished ('amazing how much we accomplished in 1.5 days'); and well-facilitated ('gradual process'; 'inductive approach'). Members wished for: a clearer vision ('more concrete sense of how to collaborate immediately') and more opportunities to network ('formal and informal time').

\section{KTTC outcomes}

From this meeting, the KTTC emerged as a uniquely trainee-initiated and trainee-led national collaborative to provide a vehicle for trainees to examine the diversity of KT research and practice, and to link trainees from diverse geographical areas and disciplines. We identify as a type of community of practice (CoP) [11] for $\mathrm{KT}$ trainees in Canada, with the underlying belief that junior researchers and practitioners can acquire valuable KT knowledge and skills, and engage in beneficial collaborative learning and working processes, through social relationships with their peers. A recent systematic review [12] identified four characteristics of CoP groups that we perceive are shared by the KTTC: members interact with one another in formal and informal settings; members share knowledge with one another; members collaborate with one another to create new knowledge; and groups promote the development of a shared, professional identity amongst members.

To date, we have created a formal collaborative, and opened to new membership in February 2011. We have identity, mission, and vision statements (Table 2), a governance structure to guide our continued growth, and working groups to develop and implement specific activities toward our collective goals [13].

We have assembled a database of current and potential collaborators, held a second meeting in May 2010 to coincide with a national conference [14] and a third meeting in April 2011 funded by another peer-reviewed grant [7], and launched a group blog hosted on a national KT website [15]. Traditional academic outputs include poster presentations at two academic conferences $[16,17]$ and a successful funding application for a follow-up meeting [7]. That trainees from this collaborative have received two peer-reviewed grants from a national health research funding agency without a traditional independent investigator is a significant achievement that speaks to the commitment and initiative of members.

\section{Moving forward}

As the meeting concluded, a number of challenges and opportunities were identified (Table 3). In order to respond to these challenges and opportunities, and particularly in order to maintain our momentum, attendees decided to devote the subsequent six to twelve months to creating a vision, governance structure, and technological infrastructure before opening the KTTC to new membership. As we plan the KTTC's future, we are challenged by our status as trainees and concerns about sustainability. Our commitment to the collaborative requires creative thinking, and belief that time invested now-in our group, career development, and collaborative learning/work-will yield future benefit. Such challenges are common in the early stages of many social innovations that eventually succeed [18], and challenges often coexist with opportunities.

\section{Key Learnings}

Three key learnings that may be applicable to other groups emerged from the meeting.

First, we found the term 'trainee' was more contentious than we had foreseen. Some members felt the term would soon cease to apply as members began their

Table 2 Identity, mission, and vision statements

\begin{tabular}{ll}
\hline Who We & The Knowledge Translation Trainee Collaborative (KTTC) is a community of practice in knowledge translation (KT). Members of the \\
Are & KTTC are junior researchers and practitioners who are interested in continuing to learn about and advance the field of KT, and who \\
& want to collaborate and build networks with other KT trainees. We define trainees as students, graduate students, postdoctoral fellows, \\
faculty, community learners, scientists/researchers from a wide spectrum of academia, healthcare professionals, healthcare \\
administrators, and/or others who are new to KT and are interested in actively exploring and developing KT research and practice. \\
\hline Vision & $\begin{array}{l}\text { We envision a sustainable network that provides accessible, ongoing opportunities for collaboration and learning; represents diversity } \\
\text { of thought in KT theory, methods and tools; and grows and advances the field of KT. }\end{array}$ \\
\hline Mission & We are creating our vision by sharing opportunities for: \\
& $\begin{array}{l}\text { 1. collaborative learning } \\
\text { 2. collaborative work } \\
\text { 3. building networks } \\
\text { 4. career development }\end{array}$
\end{tabular}


Table 3 Challenges and opportunities identified during and after the inaugural meeting

\begin{tabular}{ll}
\hline Challenges & Opportunities \\
\hline - Ensuring the KTTC achieves diversity (e.g., in research methodologies, disciplines, & - Growing academic and administrative interest in KT \\
geography, and academic vs. practice environments) & - Increasing number of KT trainees across Canada* \\
- Maintaining momentum & - Committed membership comprised of trainees from \\
- Ensuring active and effective external and internal communication & diverse backgrounds and experiences \\
- Providing value for all members (e.g., senior and junior) & - Members who value innovative thinking on and \\
- Meeting the expectations of all active members & approaches to KT \\
- Workload for members involved in administration & - A 'safer' space for trainee dialogue and discourse \\
& - Ability to complement and network with existing KT \\
& research groups and agencies \\
\hline
\end{tabular}

*The increasing number of KT trainees is reflected by the growing number of trainee awards and opportunities in Canada: e.g., the Canadian Institutes of Health Research (CIHR) now provides doctoral research awards and new investigator awards focused on KT science and KT Canada holds a Strategic Training Initiative in Health Research grant from CIHR to create an internationally-recognized national training initiative to train graduate and post-doctoral students in KT and KT science.

careers. Others, however, saw the word as one that connotes life-long learning and as applicable to KT learners (within or outside academe) at all career stages. Eventually, the group adopted the latter interpretation and clarified it in our Mission and Vision statements.

Second, as with any large group aiming for inclusivity of all members, we encountered tension between the desire for a 'flat' structure-with its potential for timeconsuming and stagnating discussions-and the inevitable hierarchy of a formal collaborative. Further, at the meeting, open-ended questions to attendees such as, 'How would you like to do this?' were sometimes more off-putting than welcomed. Ultimately, the planning committee reconciled these issues by being transparent about the 'tyranny of structurelessness' [19] and by inviting all attendees to collectively endorse some executive decision-making and organizational structure, grounded in our principles from the creating space activity. Such an endorsement later empowered the Steering Committee to make decisions required to build the collaborative.

Third, in the same way that facilitation is important in KT initiatives [20,21], we found it equally crucial in the development of our collaborative. While the continua that Harvey et al. [21] present to conceptualize facilitation might be interpreted as an either/or dichotomy (i.e., either task-oriented, doing for others, or holistic/ enabling others), our experience was one of and/both. As facilitators, we needed to provide some structure to the meeting, but also needed to ensure that each activity unfolded in a way that left all attendees feeling their contributions were authentically valued. In other words, and as Harvey et al. [21] postulate, effective facilitators need to be flexible and possess a range of task-focused and enabling skills that can be employed according to contextual needs. We relied on tenets of empowering dialogue [22] by focusing on attendees' concerns, using (inter)active learning strategies, and engaging attendees in processes to identify their needs and priorities. The integration of task and holistic facilitation, with empowering dialogue, helped us realize our meeting objectives. Beyond enabling group formation, it is our sense that strategies such as these also serve to identify and respect unique disciplinary perspectives of group members, which is essential in fostering a KT climate that espouses growth from multi- to inter-disciplinarity [23]. In this way, we feel the KTTC also serves to start addressing the challenges of cross-disciplinary collaboration.

\section{Conclusion}

Advances in KT will necessitate multiple perspectives, research approaches [2], and open cross-pollination amongst disciplines [24]. By bringing together a diverse group of trainees, the trainee-led KTTC offers the potential to complement or supplement the formal training activities of expert- or mentor-led groups, such as KT Canada, by allowing for more peer interaction and peer leadership opportunities. Through such experiences, we expect members of the collaborative to better achieve the benefits of inter- and trans-disciplinarity [23]; that is, we expect the field and our own individual research products to be improved through exposure to diverse and challenging ideas in a community of KT scholar and practitioner peers. Expanded membership and continued commitment from KT trainees will, we hope, produce further collaborative learning and work experiences that can continue to contribute to the field of $\mathrm{KT}$ and benefit other trainees in the field.

To learn more about membership in the KTTC, go to http://www.ktclearinghouse.ca/kttc/.

\section{Acknowledgements}

We are grateful for the funding received from the Canadian Institutes of Health Research (CIHR MPD grant), KT Canada and the Western Regional Training Centre for Health Services Research (WRTC) to host our inaugural meeting. We thank WRTC (and Dr. Sam Sheps) and the CIHR Institute for Health Services and Policy Research (IHSPR) (and Ms. Meg McMahon) for inkind support of our meeting, KT Canada and the Knowledge Translation Program at Li Ka Shing Knowledge Institute of St. Michael's, University of Toronto for hosting our blog, and Dr. Sharon Straus for her mentorship. We thank Ms. Isabella Losinger, WRTC manager, for her administrative support 
with managing the meeting logistics and budget. We thank Dr. lan Graham, Dr. Jamie Brehaut, Dr. Maria Mathews, and Dr. Annette J. Browne for participating in our meeting. Evelyn Cornelissen and Vivian Chan were funded by the WRTC. Robin Urquhart is funded by the CIHR/CCNS Team in Access to Colorectal Cancer Services in Nova Scotia and the Nova Scotia Health Research Foundation. Ryan DeForge is funded through a CIHR Frederick Banting - Charles Best Canada Graduate Scholarship - Doctoral Research Award. Heather Colquhoun is funded through a CIHR Strategic Training Fellowship in Rehabilitation Research, a CIHR Doctoral Scholarship, and the Canadian Occupational Therapy Foundation. Shannon Sibbald is a Canadian Health Services Research Foundation post-doctoral fellow based at the University of Western Ontario. Holly Witteman holds a post-doctoral fellowship at the University of Michigan funded by grants from the U. S. National Institutes of Health (R01 CA087595 and P50 CA101451).

\section{Author details}

'University of British Columbia - Okanagan, Faculty of Health and Social Development, 3333 University Way, Kelowna, B.C. V1V 1V7 Canada. ${ }^{2}$ Dalhousie University, Interdisciplinary PhD Program, 1276 South Park Street; Room 804, Victoria Building; Halifax, N.S. B3H 2 Y9 Canada. ${ }^{3}$ University of British Columbia, Interdisciplinary Studies Graduate Program, Green College. Green Commons, Room 153A, 6201 Cecil Green Park Rd; Vancouver, B.C. V6T 1 Z1 Canada. ${ }^{4}$ The University of Western Ontario, Faculty of Health Sciences, 1151 Richmond St; London, O.N., N6A 5B9 Canada. ${ }^{5}$ McMaster University, School of Rehabilitation Sciences, IAHS Building; 1400 Main St. W.; Hamilton, O.N., L8S 1C7 Canada. ' University of Western Ontario, Faculties of Health Sciences and Information and Media Studies, 1151 Richmond St; London, O. N., N6A 5B9 Canada. ${ }^{7}$ University of Michigan, Center for Bioethics and Social Science in Medicine, 300 North Ingalls Building 7C27, Ann Arbor, M.I. 481095429 USA.

\section{Authors' contributions}

EC developed the outline of the paper, coordinated the content from all authors, and prepared the first draft with assistance from RU and HW. All authors contributed to the final content. EC, RU, VC, and HW edited the final draft. $E C, R D, H W, R U$, and $H C$ revised the manuscript according to reviewers' comments. All authors have read and approved the final manuscript.

\section{Competing interests}

The authors declare that they have no competing interests.

Received: 28 January 2011 Accepted: 25 August 2011

Published: 25 August 2011

\section{References}

1. Graham I, Tetroe J: Whither Knowledge Translation: An International Research Agenda. Nursing Research 2007, 56(4 Suppl):S7-S23.

2. Kitson $\mathrm{A}$ : The need for systems change: reflections on knowledge translation and organizational change. Journal of Advanced Nursing 2009, 65(1):217-228.

3. KT Canada. [http://ktclearinghouse.ca/ktcanada/education/summerinstitute], retrieved Nov. 2, 2010.

4. Kho M, Estey E, DeForge R, Mak L, Bell B: Riding the knowledge translation roundabout: lessons learned from the Canadian Institutes of Health Research Summer Institute in knowledge translation. Implementation Science 2009, 4(33).

5. Leung B, Catallo C, Riediger N, Cahill N, Kastner M: The trainees' perspective on developing an end-of-grant knowledge translation plan. Implementation Science 2010, 5(1):78.

6. Chan V, Cornelissen E: Developing a Student Community of Practice in KT Research. CIHR Meetings, Planning, Dissemination Grant - Knowledge Translation competition 2009, [awarded] \$15,000 CAD.

7. Cornelissen E, Urquhart R, Colquhoun H, DeForge R, Emberly D, Richmond S, Witteman H: Towards planning a sustainable knowledge translation trainee collaborative. CIHR Meetings, Planning, Dissemination Grant - Planning Grants, Spring 2010 competition, [awarded] \$25, 000 CAD.

8. Dr. Jamie Brehaut. [http://www.ohri.ca/profiles/brehaut.asp], retrieved Jan. 12, 2011.

9. Dr. Maria Matthews. [http://www.med.mun.ca/Medicine/Faculty/Mathews, Maria.aspx], retrieved Jan. 12, 2011.
10. Dr. Annette J. Browne. [http://www.nursing.ubc.ca/faculty/biopage.aspx? c=70.8731260775197], retrieved Jan. 12, 2011.

11. Wenger E, McDermott RA, Snyder W: Cultivating Communities of Practice Boston, MA: Harvard Business School Press; 2002.

12. Li LC, Grimshaw JM, Nielsen C, Judd M, Coyte PC, Graham ID: Use of communities of practice in business and health care sectors: a systematic review. Implementation Science 2009, 4(27).

13. KT Trainee Collaborative terms of reference. [http://ktclearinghouse.ca/ kttc/about/, retrieved Jan. 18, 2011

14. Canadian Association for Health Services and Policy Research annual conference. [https://cahspr.ca/], retrieved Jan. 18, 2011.

15. KT Trainee Collaborative. [http://ktclearinghouse.ca/kttc/], retrieved Jan. 18, 2011.

16. Colquhoun $\mathrm{H}$, Chan V, Cornelissen E, Urquhart R: A knowledge translation trainee collaborative. Knowledge Translation 2010: Improving Health Care and Health Systems with Knowledge Translation 2010, Halifax, Nova Scotia, (poster).

17. Urquhart R, Chan V, Cornelissen E, Colquhoun H: Development of a national knowledge translation trainee collaborative towards advancing the field of knowledge translation in Canada. Family Medicine Forum 2010 2010, Vancouver, (poster).

18. Westley F, Zimmerman B, Patton MQ: Getting to maybe: how the world is changed Toronto: Vintage Canada, Random House of Canada Limited; 2007.

19. Freeman J: The tyranny of structurelessness. Berkeley Journal of Sociology 1972, 17:151-165.

20. Kitson A, Harvey G, McCormack B: Enabling the implementation of evidence based practice: A conceptual framework. Quality in Health Care 1998, 7(3):149-158.

21. Harvey G, Loftus-Hills A, Rycroft-Malone J, Titchen A, Kitson A, McCormack B, et al: Getting evidence into practice: The role and function of facilitation. Journal of Advanced Nursing 2002, 37(6):577-588.

22. Freiré P: Education for Critical Consciousness New York: Continuum; 1973.

23. Choi BCK, Pak AWP: Multidisciplinarity, interdisciplinarity and transdisciplinarity in health research, services, education and policy: 1. Definitions, objectives, and evidence of effectiveness. Clinical and Investigative Medicine 2006, 29(6):351-364.

24. Lather L: Paradigm proliferation as a good thing to think with: teaching research in education as a wild profusion. International Journal of Qualitative Studies in Education 2006, 19(1):35-57.

doi:10.1186/1748-5908-6-98

Cite this article as: Cornelissen et al: Creating a knowledge translation trainee collaborative: from conceptualization to lessons learned in the first year. Implementation Science 2011 6:98.

\section{Submit your next manuscript to BioMed Central and take full advantage of:}

- Convenient online submission

- Thorough peer review

- No space constraints or color figure charges

- Immediate publication on acceptance

- Inclusion in PubMed, CAS, Scopus and Google Scholar

- Research which is freely available for redistribution

Submit your manuscript at www.biomedcentral.com/submit
C Biomed Central 